Special issue of the 2nd International Conference on Computational and Experimental Science and Engineering (ICCESEN 2015)

\title{
The Effect of Nugget Sizes on Mechanical Properties in Resistance Spot Welding of S235JR(Cu) Steel Sheets Used in Railway Vehicles
}

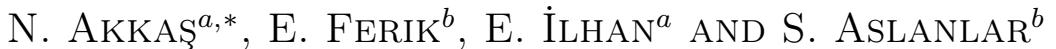 \\ ${ }^{a}$ Sakarya University, Faculty of Technical Education, Sakarya, Turkey \\ ${ }^{b}$ Sakarya University, Faculty of Technology, Sakarya, Turkey
}

\begin{abstract}
This paper presents an experimental study on the resistance spot welding of $\mathrm{S} 235 \mathrm{JR}(\mathrm{Cu})$ steel sheets used in side walls and roofs of rail vehicle bodies. A timer and current controlled resistance spot welding machine having $120 \mathrm{kVA}$ capacity and a pneumatic application mechanism with a single lever were used to prepare the specimens. Welding duration was chosen to be 5, 10, 15, 20, 25 and 30 periods ( 1 period $=0.02$ s) and also welding currents were increased from $6 \mathrm{kA}$ up to $14 \mathrm{kA}$ in steps of $0.5 \mathrm{kA}$. The electrode force was kept constant at $6 \mathrm{kN}$. The obtained welding joints were exposed to tensile peel and tensile shear tests and their nugget sizes were measured by means of an optical microscope. The effect of nugget sizes on tensile peel strength and tensile-shear strength was determined using weld lobe diagrams. Based on this data the optimum welding currents and times were advised.
\end{abstract}

DOI: $10.12693 /$ APhysPolA.130.60

PACS/topics: $81.20 . \mathrm{Vj}, 06.60 . \mathrm{Vz}$

\section{Introduction}

Resistance spot welding (RSW) is the common method most widely used to join metal sheets, particularly in automotive industry. Typically, there are about 2000-5000 spot welds in a modern vehicle [1]. RSW has excellent techno-economic benefits such as low cost, high speed and suitability for automation [2].

Weld nugget size is the most important parameter determining the mechanical behaviour of the RSW joint. Quality and strength of the spot welds are defined by shape and size of weld nuggets [3]. Besides, the tensileshear and tensile-peel strength of the joint in RSW is an important index of welding quality [4]. In most cases, good spot-welding practice requires three parameters that have to be controlled, namely, current, time, and electrode force [5].

Therefore, measurements of nugget size were used to correlate welding input parameters and mechanical properties of the weld.

Various industry standards recommend the optimum or minimum size of the spot weld for a given sheet metal thickness. For example, the American Welding Society (AWS), Society of Automotive Engineering (SAE), and the American National Standards Institute (ANSI) [6] together recommend a weld nugget width given by

$$
d_{1}=4 s^{0.5},
$$

for steels, where $d_{1}$ and $s$ are the weld nugget width and thickness of the workpiece (in $\mathrm{mm}$ ), respectively.

$\mathrm{S} 235 \mathrm{JR}(\mathrm{Cu})$ grade steel sheets which are known as non-alloy steels for structural purposes and are widely

\footnotetext{
*corresponding author; e-mail: akkas.nuri@gmail.com
}

used in the petroleum, petrochemical, water conservancy, electric power, food, brewing, shipbuilding, marine engineering and rail transportation were used in this study.

The purpose of this work was to investigate the effect of nugget sizes on tensile strength in RSW of $\operatorname{S} 235 \mathrm{JR}(\mathrm{Cu})$ steel sheets. The macrostructure of the welded samples was evaluated. The samples were exposed to tensileshear and tensile-peel tests in order to determine the joint strengths. The effect of nugget sizes on tensileshear strength and tensile-peel strength was determined by using weld lobe diagrams and based on this data the optimum welding currents and times were advised.

\section{Experimental studies}

During the RSW experiments such parameters as the electrode form, type of welded material, cooling water flow rate and electrode force were kept constant and only the welding current and the welding time were varied. All series were exposed to tensile shear and tensile peel tests in order to determine the joint strengths.

\subsection{Materials}

The studied materials were $\mathrm{S} 235 \mathrm{JR}(\mathrm{Cu})$ steel sheets having thicknesses of $2 \mathrm{~mm}$, which are used in constructing side walls and roofs of rail vehicle bodies. The chemical composition and the mechanical properties of the sheets are shown in Tables I and II, respectively.

TABLE I

Chemical composition of steel sheets used in experiments [wt.\%]. 
TABLE II

Mechanical properties of the sheet steel.

\begin{tabular}{c|c}
\hline \hline Yield strength [MPa] & 320 \\
Tensile strength [MPa] & 435 \\
Total elongation [\%] & 52
\end{tabular}

\subsection{Welding equipment}

A timer and current controlled RSW machine, having 120 kVA capacity, and a pneumatic application mechanism with a single lever were used in the experiments. The electrode force was continuously measured and controlled during the experiments. And also welding current values were continuously calculated and controlled by means of a current transformer, placed on the lever of the welding machine, and an ampere-meter. Welding time, holding time and clamping time were adjusted automatically by electronic devices of the machine. Welding was carried out by using water cooled conical $\mathrm{Cu}-\mathrm{Cr}$ electrodes, having a contact surface of constant diameter $(7 \mathrm{~mm})$.

\subsection{Welding process}

Tensile-shear and tensile-peel specimens were prepared in accordance with EN ISO 14273 [7] and EN ISO 14270 [8] standards, respectively, as shown in Fig. 1 and 2. After that, welded parts were put together with

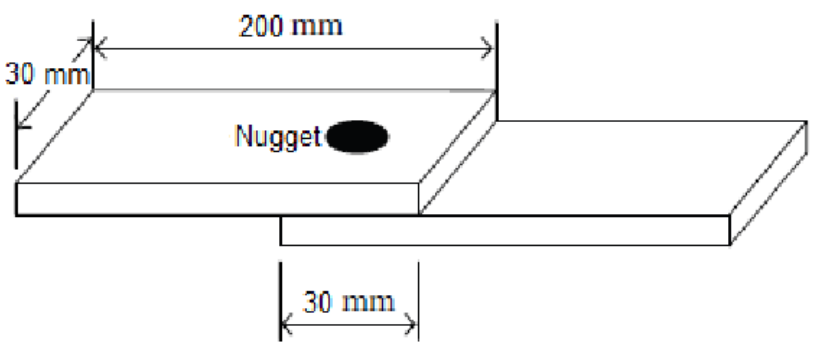

Fig. 1. Tensile-shear specimens.

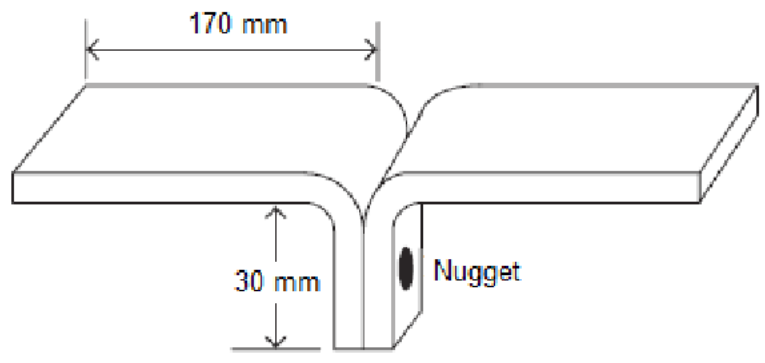

Fig. 2. Tensile-peel specimens.

overlapping of $30 \mathrm{~mm}$ and welded in accordance with EN ISO 14373 [9] standard. For joining, the welding time of $5,10,15,20,25$ and 30 periods were applied, while other welding parameters, such as applied electrode force $(6 \mathrm{kN})$, clamping and holding times of electrode (25 periods) were kept constant. The welding current was increased from $6 \mathrm{kA}$ to $14 \mathrm{kA}$ in $0.5 \mathrm{kA}$ increments.

\subsection{Tensile strength and nugget size}

All series were exposed to tensile-shear and tensilepeel tests in a testing machine in laboratory conditions. The tensile speed had remained constant during the tests. The values given as the tensile-shear and tensile-peel strength are the maximum values taken from the scale of the machine.

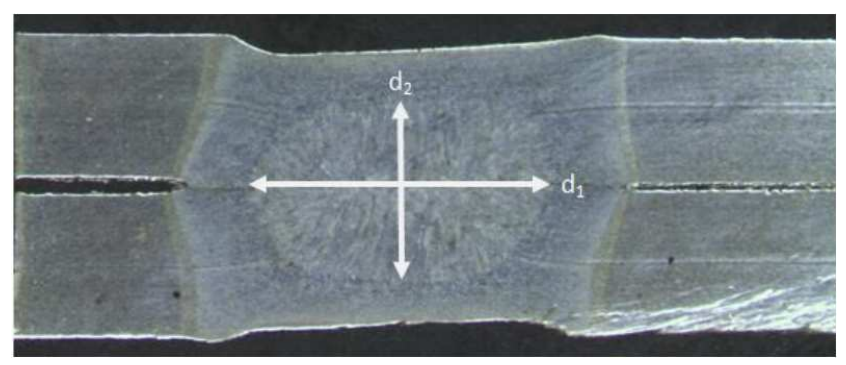

Fig. 3. Weld nugget geometry.

Nugget widths $d_{1}$ and nugget heights $d_{2}$ were measured using an optical microscope and nugget size ratios $d_{2} / d_{1}$ were calculated. Weld nugget geometry is shown in Fig. 3. The effect of nugget size on tensile-shear and tensile-peel strength was investigated by gathering obtained results in diagrams.

\section{Results}

The effect of nugget width, nugget height and nugget size ratio on tensile-shear and tensile-peel strength were determined and discussed. Such parameters as nugget width or nugget height are not enough to explain the effect of welding nugget size on tensile-shear and tensilepeel strengths of the joints. Therefore, nugget size ratio is also used for this purpose [10,11].

At application of low welding current, small weld nugget widths and similarly lower tensile-shear and tensile-peel strength values were obtained, compared to those of base-metal, due to application of low amount of heat to the welding zone [12-15].

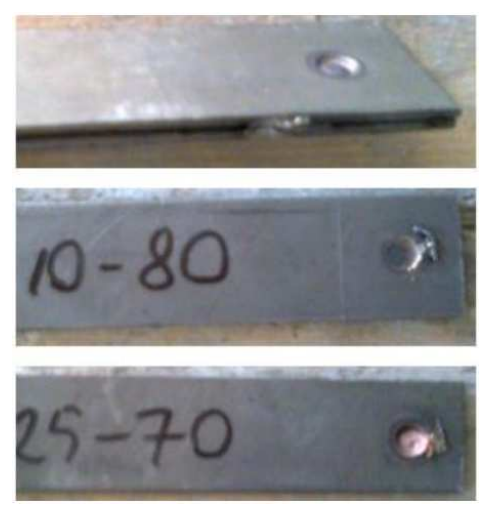

Fig. 4. Spurt out failure observed in weld nuggets.

At application of long welding time and high welding current, weld nugget spurts out between the two sheets, 
resulting in the decrease of the width. At the same time, an over-coloured, retained structure with deep electrode marks and deformations is formed in the weld zone, as shown in Fig. 4. This may be the reason for the decreasing trend of tensile-shear and tensile-peel strength. shown in Figs. 5a and 6a [12-15].
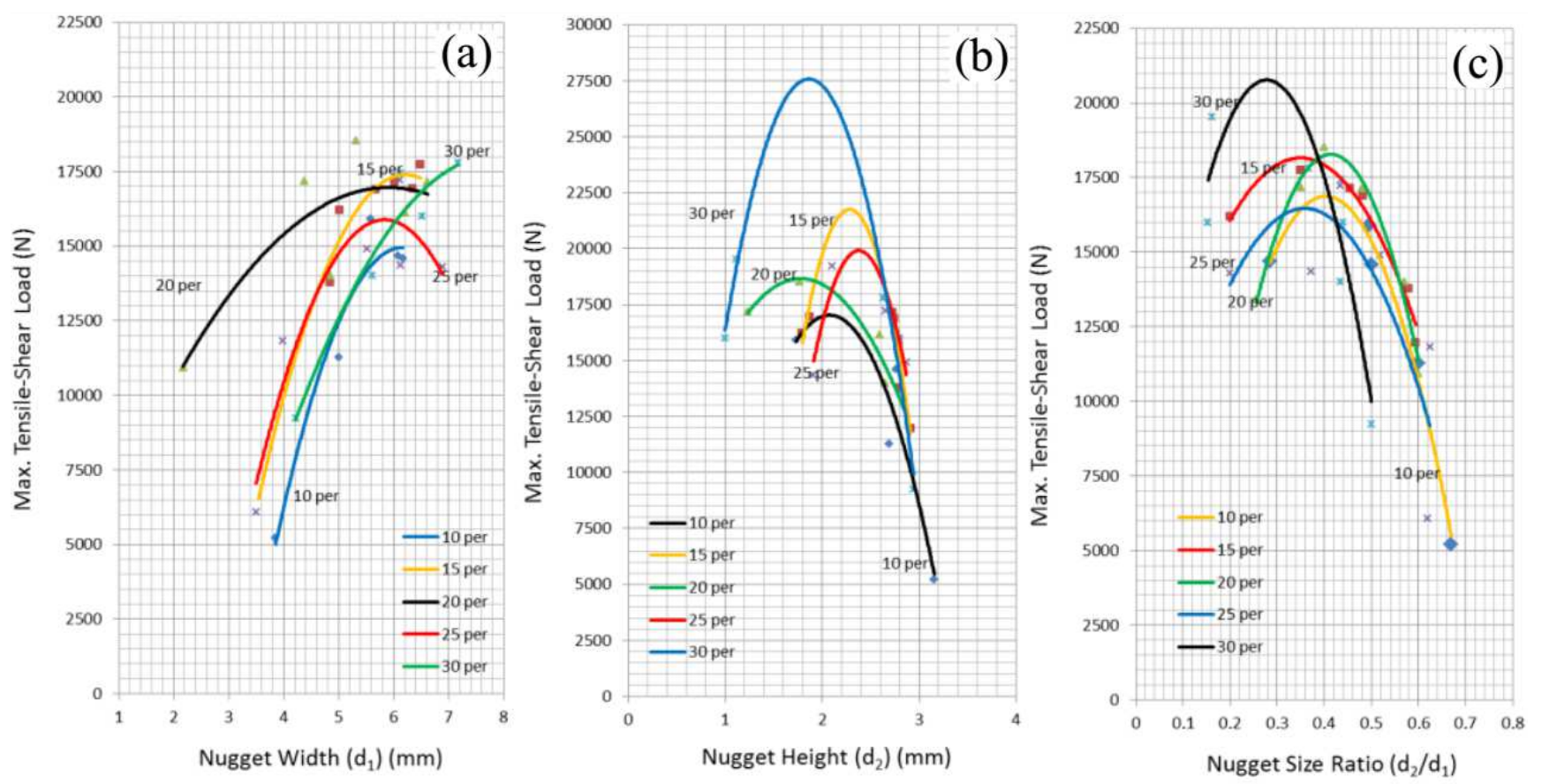

Fig. 5. The effect of nugget width (a), height (b) and size ratio (c) on tensile-shear load.
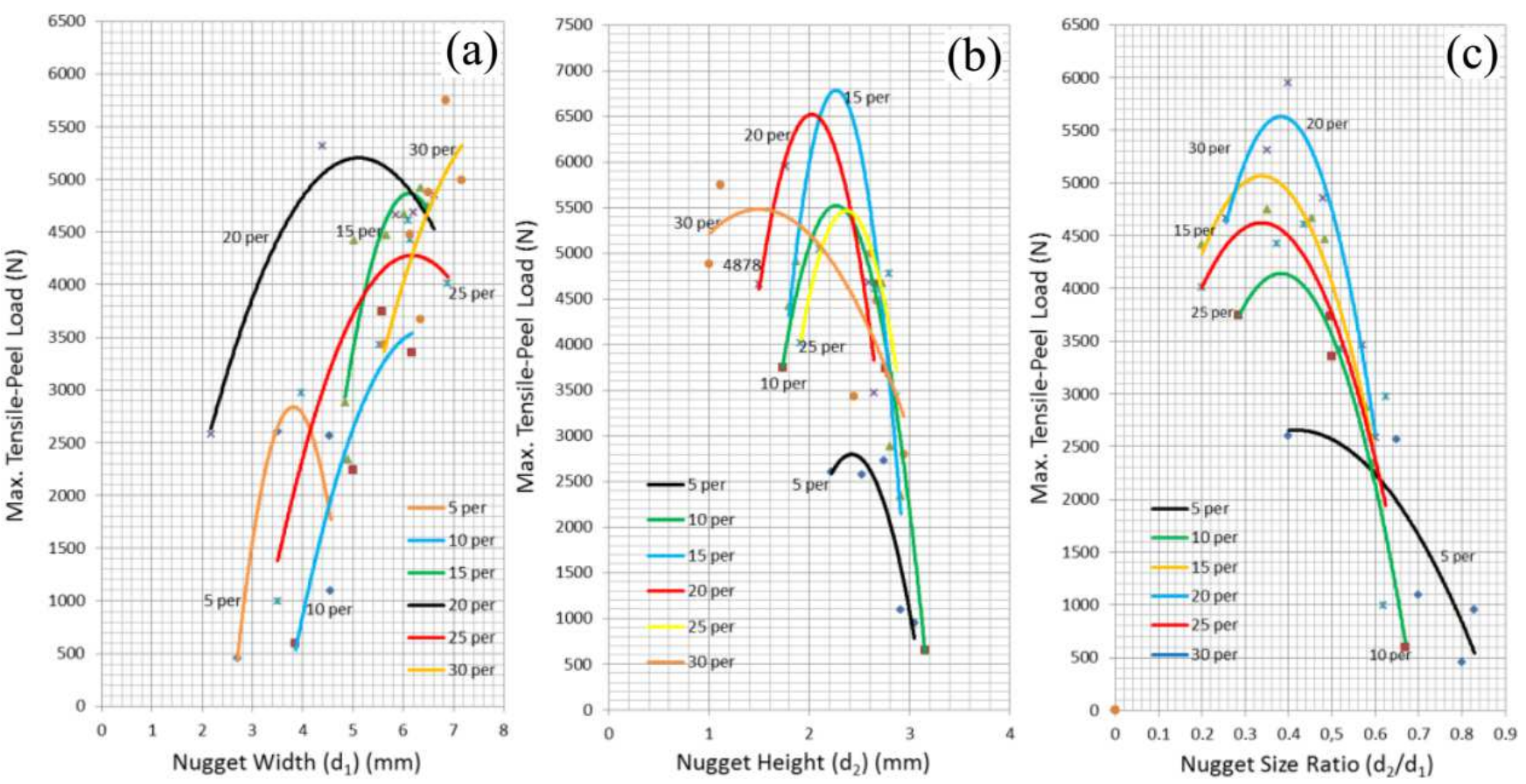

Fig. 6. The effect of nugget width (a), height (b) and size ratio (c) on tensile-peel load.

As a result of nugget width increment, the tensile-shear strength rises up to widths of $6-7 \mathrm{~mm}$ and then tensileshear strength starts to decrease at nugget width above
$7 \mathrm{~mm}$, as shown in Fig. 5a. In addition, the maximum tensile-shear strength was obtained at nugget height of 1.5-2 mm, as shown in Fig. 5b. Similarly, the maximum 
tensile-peel strength was obtained at nugget height of 1.5-2 $\mathrm{mm}$, as shown in Fig. 6b. When the nugget size ratio diagrams were investigated with respect to tensileshear and tensile-peel strengths, it was seen that the maximum strength value was obtained at nugget size ratio of 0.24-0.26, as shown in Figs. 5c and 6c.

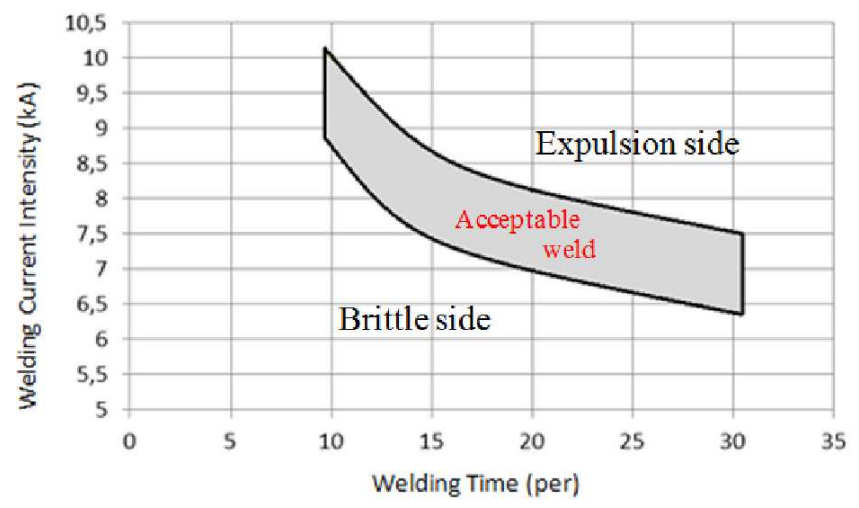

Fig. 7. Weld lobe curve.

The weldability lobe diagram was specified for tensileshear and peel tests to determine the upper and lower limits of welding current and time for RSW. The brittle and expulsion limits are shown. The width of the acceptable welds can be changed according to the sheet thickness, material type, heat treatment, and surface condition. Figure 7 shows the specific lobe curve for $\operatorname{S235JR}(\mathrm{Cu})$ steel with nominal thickness of $2 \mathrm{~mm}$. It can be seen in Fig. 7 that welding current of $7.5 \mathrm{kA}$ gives the widest range of acceptable welding time.

\section{Conclusions}

As a result of the work performed at electrode force of $6 \mathrm{kN}$, the following conclusions and suggestions can be made.

In the joining of $\mathrm{S} 235 \mathrm{JR}(\mathrm{Cu})$ steel sheets, maximum tensile-shear strength is obtained at welding current of $8 \mathrm{kA}$ applied during 30 periods. The $30 \%$ sheet thickness limit is exceeded at this condition. Additionally deep electrode indentations, excessive deformations, colour changes in welding zone and over-melting due to excessive heat input may occur. When the high surface quality is preferred to strength, $7 \mathrm{kA}$ welding current for 25 periods of welding time or $7.5 \mathrm{kA}$ welding current for 20 periods of welding time are enough.
In the joining of $\mathrm{S} 235 \mathrm{JR}(\mathrm{Cu})$ steel sheets, maximum tensile-peel strength is obtained at $9 \mathrm{kA}$ welding current applied during 20 periods. This value is approximately a quarter of the one obtained in tensile-shear strength, which shows the sensitivity of $\operatorname{S} 235 \mathrm{JR}(\mathrm{Cu})$ sheets welded by RSW to tensile-peel forces.

\section{References}

[1] F. Khodabakhshi, M. Kazeminezhad, A.H. Kokabi, Mater. Charact. 69, 71 (2012).

[2] S. Aslanlar, A. Ogur, U. Ozsarac, E. Ilhan, Mater. Design 29, 1427 (2008).

[3] H. Moshayedi, I. Sattari-Far, J. Mater. Proc. Technol. 212, 347 (2012).

[4] M. Zhou, H. Zhang, S.J. Hu, Weld. J. 4, 72 (2003).

[5] A.M. Al-Mukhtar, Q. Doos, Adv. Mater. Sci. Eng. 2013, 1 (2013).

[6] American Welding Society, Recommended practices for test methods and evaluation the resistance spot welding behavior of automotive sheet steels, AWS D8.9 (1997).

[7] Turkish Standards Institution, Specimen dimensions and procedure for shear testing resistance spot, seam and embossed projection welds, TS EN ISO 14273 (2002).

[8] Turkish Standards Institution, Specimen dimensions and procedure for mechanized peel testing resistance spot, seam and embossed projection welds, TS EN ISO 14270 (2002).

[9] Turkish Standards Institution, Resistance welding Procedure for spot welding of uncoated and coated low carbon steels, TS EN ISO 14373 (2008).

[10] S. Anık, B. Gulbahar, 2nd National Welding Symposium, Proceedings, Istanbul 1989, p. 94.

[11] M. Vural, Ph.D. Thesis, ITU, Istanbul, Turkey 1992.

[12] N. Akkaş, E. İlhan, S. Aslanlar, F. Varol, Mater. Testing 56, 879 (2014).

[13] N. Akkas, E. İlhan, Acta Phys. Pol. A 125, 497 (2014).

[14] N. Akkas, F. Varol, E. Ferik, E. İlhan, U. Ozsarac, S. Aslanlar, Acta Phys. Pol. A 125, 500 (2014).

[15] S. Aslanlar, A. Ogur, U. Ozsarac, E. Ilhan, Z. Demir, Mater. Design 28, 2 (2007). 